\title{
The Study of Frost Occurrence in Free State Province of South Africa
}

\author{
Mokhele Edmond Moeletsi, ${ }^{1,2}$ Mphethe Tongwane, ${ }^{1}$ and Mitsuru Tsubo ${ }^{1}$ \\ ${ }^{1}$ ARC-Institute for Soil, Climate and Water, Private Bag X79, Pretoria 0001, South Africa \\ ${ }^{2}$ Risks and Vulnerability Assessment Centre, University of Limpopo, Private Bag X1106, Sovenga 0727, South Africa
}

Correspondence should be addressed to Mokhele Edmond Moeletsi; moeletsim@arc.agric.za

Received 5 April 2016; Revised 16 July 2016; Accepted 2 August 2016

Academic Editor: Anthony R. Lupo

Copyright (C) 2016 Mokhele Edmond Moeletsi et al. This is an open access article distributed under the Creative Commons Attribution License, which permits unrestricted use, distribution, and reproduction in any medium, provided the original work is properly cited.

\begin{abstract}
The study investigated the cessation, onset, and duration of light, medium, and heavy frost in Free State province of South Africa using minimum temperatures from 1960 to 2015. Trends in the frost indices were assessed using the Man-Kendall test. Onset of frost varied spatially with earlier onset over the northern, eastern, and southeastern parts. Areas of early onset also experience late cessation of frost resulting in shorter growing period of less than 240 days. The western parts have longer growing period exceeding 240 days due to earlier cessation of frost and relatively late onset of frost. Trends for the frost-free period (growing period) show contrasting negative and positive trends with isolated significant trends.
\end{abstract}

\section{Introduction}

Maize (Zea mays) is a major crop in Sub-Saharan Africa as it forms a staple food of most people in the region [1]. South Africa is amongst the ten highest maize producing countries in the world with an average of 12 million tonnes per year, contributing approximately $2 \%$ of the world's maize production [2]. Free State province produces over $35 \%$ of the maize in South Africa [3]. However, the average maize yield for the province varies greatly from one year to another, mainly, due to climate variability [4]. Overall the environmental conditions and natural resources of Free State are conducive for maize production but there are also agroclimatological hazards that have a detrimental effect on production $[4,5]$. These restrictive occurrences include drought, late cessation of frost that damages early planted crops, early onset of frost affecting crops at later stages of their growth, sporadic hail occurrence, and low temperatures during the growing period resulting in reduced maize crop production $[6,7]$.

Apart from drought, farmers consider frost as the major hazard that influences their year to year production [8]. On an annual basis across most frost-prone countries, onset of frost in autumn and cessation of frost in spring cause damage to late planted or long-season crops and early planted crops during the early vegetative stage, respectively [9]. There are four main characteristics of frosts: the onset of frost or first frost date, cessation of frost or last frost date, duration of the frost-free or frost period, and the frequency of frosts. The cessation of frost in southern Africa marks the beginning of the growing period which occurs mostly during the months of September and October, while the onset of frost indicates that the growing period of most summer crops is coming to an end, which normally occurs in April, May, and June [5]. Studies by Tait and Zheng [10], Rahimi et al. [11], and Varshavian et al. [9] emphasized the importance of frost analyses, especially how knowledge about the frequency and timing of frosts will help reduce the risk of damage in frost vulnerable areas as well as minimizing future frost damage. Due to the interannual variability of frost, continuous updating of frost dates is necessary to reflect recent climatic events [12].

Different temperature thresholds are used for determining frost. For example, Zenoni et al. [13] studied the risk related to late frost using five different thresholds $\left(-1^{\circ} \mathrm{C},-2^{\circ} \mathrm{C}\right.$, $-3^{\circ} \mathrm{C},-4^{\circ} \mathrm{C}$, and $\left.-5^{\circ} \mathrm{C}\right)$. Hejazizadeh and Naserzadeh [14] categorized frost as weak $\left(0^{\circ} \mathrm{C}\right.$ to $\left.2^{\circ} \mathrm{C}\right)$, moderate $\left(-2^{\circ} \mathrm{C}\right.$ to $-4^{\circ} \mathrm{C}$ ), or severe (below $-4^{\circ} \mathrm{C}$ ) in Iran. Trasmonte et al. [15] 
studied the frost risk in the Mantaro River basin of Peru using the following limits: $5^{\circ} \mathrm{C}, 2.5^{\circ} \mathrm{C}, 0^{\circ} \mathrm{C},-2^{\circ} \mathrm{C}$, and $-4^{\circ} \mathrm{C}$. The threshold to use has to be specific according to a crop of interest but different thresholds can also be used to show severity of frost risk or to accommodate a variety of crops. Grain crops including maize freeze at temperatures below $0^{\circ} \mathrm{C}$, so a screen temperature of $0^{\circ} \mathrm{C}$ is a suitable indicator of damaging frost [16]. The critical temperature for maize is between $-1^{\circ} \mathrm{C}$ and $-2^{\circ} \mathrm{C}$ [17]. Trasmonte et al. [15] used the $5^{\circ} \mathrm{C}$ threshold to determine the frost risk analysis for the maize crop due to its sensitivity to low temperatures.

The risk of frost varies greatly in Free State province due to the contrasting topography and geographical aspect. Thus, there is a need to investigate the variability of the frost indices in the region and their impact on agricultural production. In this study, frost risk for dryland maize production in Free State was assessed using three thresholds: $-2^{\circ} \mathrm{C}, 0^{\circ} \mathrm{C}$, and $2^{\circ} \mathrm{C}$. These thresholds have been determined based on previous studies in other regions [11, 13-17]. Three main indices were determined for each threshold: onset of frost, cessation of frost, and duration of frost-free period. Trends in these indices were assessed at selected stations in Free State with data from 1960 to 2015.

\section{Data and Methods}

2.1. Data. All the data used was obtained from the Agricultural Research Council (ARC) and the South African Weather Service (SAWS). The daily minimum temperature dataset was used in the analysis for determination of frost risk assessment in Free State province. The data used in the study was recorded inside a Stevenson screen elevated at $1.3 \mathrm{~m}$ above ground level. The data was arranged by agricultural season (July to June). Nine stations scattered in different parts of the province were selected with data efficiency exceeding 70\% from 1960 to 2015 (Figure 1; Table 1).

Where necessary, the data was patched with the UK traditional method which uses the nearest neighbour stations (up to five) to determine average temperature values in a particular month and then uses the differences (target station long-term mean temperature - neighbour station long-term mean temperature) in values to patch within that month [18]. A patched value is taken from the average of all the predicted values from each nearby station.

\subsection{Methods}

2.2.1. Determination of Frost Occurrence. The data was arranged according to agricultural season from July to June of the following year. For each season the last day of frost in spring (cessation of frost) and the first day of frost in autumn (onset of frost) were determined at each of the stations and for each year. Screen temperatures of greater than $0^{\circ} \mathrm{C}$ upper bounded by $2^{\circ} \mathrm{C}$ are considered as light frost. Minimum temperatures recorded on the screen greater than $-2^{\circ} \mathrm{C}$ upper bounded by $0^{\circ} \mathrm{C}$ are considered as medium frost, while minimum temperatures of $-2^{\circ} \mathrm{C}$ or lower represent heavy frost. The frost dates were converted to Julian days to facilitate statistical computations. The frost-free period
TABLE 1: Information for climate stations in Free State province used in the frost assessment study.

\begin{tabular}{lrccc}
\hline Station & Latitude & Longitude & Altitude $(\mathrm{m})$ & Region \\
\hline Bethlehem & -28.1626 & 28.2953 & 1631 & Northeastern \\
Bloemfontein & -28.9500 & 26.3333 & 1304 & Central \\
Bothaville & -27.4000 & 26.5000 & 1280 & Northern \\
Fauresmith & -29.7700 & 25.3200 & 1522 & Southwestern \\
Ficksburg & -28.8667 & 27.8500 & 1829 & Eastern \\
Frankfort & -27.2667 & 28.5000 & 1502 & Northeastern \\
Virginia & -28.1000 & 26.8667 & 1335 & Northwestern \\
Wepener & -29.7333 & 27.0333 & 1438 & Southeastern \\
Zastron & -30.3000 & 27.0830 & 1661 & Southeastern \\
\hline
\end{tabular}

for each agricultural season was then calculated for light, medium, and heavy frost occurrences as the number of days between last and first frost. The frost-free period is the most important index which marks the length of the growing period for most crops in the high lying regions.

2.2.2. Statistical Analysis. Minitab software was used to determine the appropriate probability distribution for all the variables (onset, cessation, and frost period) at each station. All the data for different frost indices at thresholds were tested for the following distributions at 95\% confidence level: Normal, LogNormal, Gamma, Exponential, Weibull, Logistic, and LogLogistic. The best distribution was selected based on the highest significant $(>0.05) p$ values. The onset of frost, cessation of frost, and frost-free period were determined for different probability levels based on the selected distribution to assess frost occurrence in Free State province. To clearly show the risk associated with the onset of frost, cessation of frost, frost period, and frost-free period, the exceedance probability was used for the cessation of frost while the nonexceedance probability was used for the other frost indices.

2.2.3. Trends in Frost Incidences. To determine whether there are trends in the onset of frost, cessation of frost, and duration of frost, the Man-Kendall test was carried out at 95\% and 90\% confidence levels.

\section{Results}

Frost indices varied widely throughout Free State province. The analysis of frost probabilities is at 20\%, $50 \%$, and $80 \%$ nonexceeding/exceeding showing a return period of 4 in 5 years for nonexceeding( 1 in 5 years for exceeding), 1 in 2 years, and 1 in 5 years for nonexceeding ( 4 in 5 years for exceeding), respectively.

3.1. Distribution Fitting. The best-fit distribution for the cessation of frost at $2^{\circ} \mathrm{C}, 0^{\circ} \mathrm{C}$, and $-2^{\circ} \mathrm{C}$ is LogNormal, LogNormal, and Normal, respectively (Table 2). Onset of frost for all the thresholds mainly followed the Normal distribution in Free State province. Normal distribution was 
TABLE 2: Distribution fitting of frost indices at different thresholds $\left(2^{\circ} \mathrm{C}, 0^{\circ} \mathrm{C}\right.$, and $\left.-2^{\circ} \mathrm{C}\right)$.

\begin{tabular}{lccccccccc}
\hline \multirow{2}{*}{ Station } & \multicolumn{3}{c}{ Cessation of frost } & \multicolumn{3}{c}{ Onset of frost } & \multicolumn{3}{c}{ Duration of frost } \\
& $2{ }^{\circ} \mathrm{C}$ & $0{ }^{\circ} \mathrm{C}$ & $-2^{\circ} \mathrm{C}$ & $2^{\circ} \mathrm{C}$ & $0{ }^{\circ} \mathrm{C}$ & $-2^{\circ} \mathrm{C}$ & $2^{\circ} \mathrm{C}$ & $0^{\circ} \mathrm{C}$ & $-2^{\circ} \mathrm{C}$ \\
\hline Bethlehem & Normal & LogNormal & LogLogistic & Logistic & Normal & Normal & Normal & Weibull & Weibull \\
Bloemfontein & LogNormal & LogNormal & Normal & Normal & Normal & Normal & Normal & Normal & Normal \\
Bothaville & LogNormal & LogNormal & Weibull & Normal & Logistic & LogNormal & Normal & Normal & Normal \\
Fauresmith & Normal & LogNormal & Normal & LogNormal & Normal & LogNormal & LogNormal & Normal & LogNormal \\
Ficksburg & LogNormal & LogNormal & LogNormal & Normal & Normal & Normal & LogNormal & Normal & Normal \\
Frankfort & Normal & Normal & Normal & Weibull & Normal & Normal & Normal & Weibull LogNormal & LogNal \\
Virginia & LogNormal & LogNormal & Normal & Normal & Normal & Normal & Weibull & Weibull & Normal \\
Wepener & Normal & LogNormal & LogLogistic & Normal & Normal & Normal & LogLogistic & Weibull & Normal \\
Zastron & Gamma & LogNormal & LogLogistic & Normal & Normal & Normal & Normal & Weibull & Normal \\
\hline
\end{tabular}

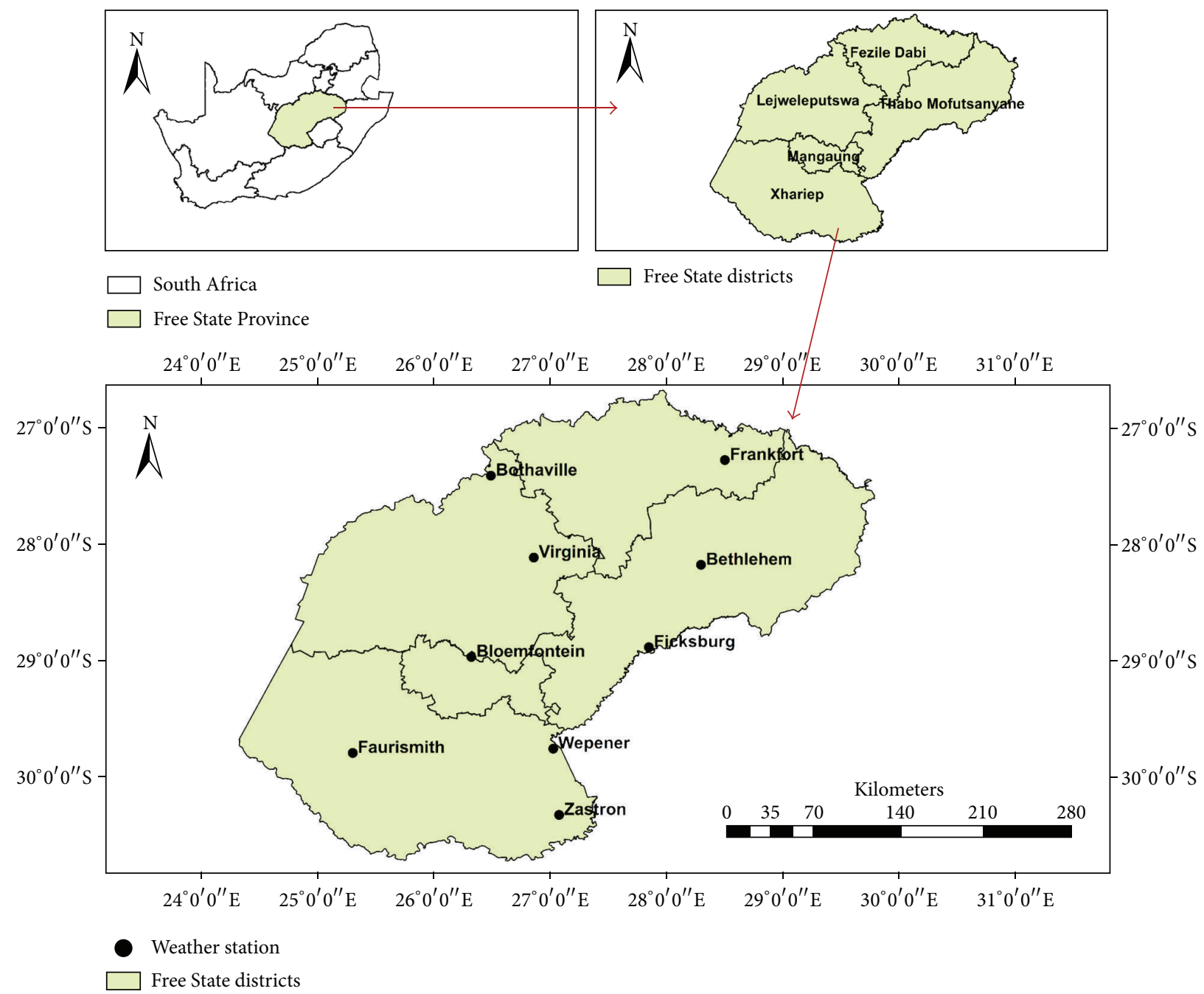

FIGURE 1: Distribution of the weather stations used in the analysis of frost in Free State province of South Africa.

the dominant distribution for the duration of frost followed by the Weibull distribution which is mostly evident at the frost threshold of $0^{\circ} \mathrm{C}$. These distributions were significant at 95\% confidence level and showed highest $p$ values amongst all the distributions. Figure 2 shows an example of probability fitting for the Bethlehem station. The results of the
Kolmogorov-Smirnov test yielded a $p$ value of 0.76 for the Normal distribution which is significant at $95 \%$.

3.2. Cessation of Frost. Cessation of frost in Free State as shown in Figure 3 and Table 3 occurs earliest in the areas surrounding Virginia and Bothaville over northern parts of 
TABLE 3: Cessation of frost at different probability levels $(20 \%, 50 \%$, and $80 \%)$ and thresholds $\left(2^{\circ} \mathrm{C}, 0^{\circ} \mathrm{C}\right.$, and $\left.-2^{\circ} \mathrm{C}\right)$.

\begin{tabular}{|c|c|c|c|c|c|c|c|c|c|}
\hline \multirow{2}{*}{ Station } & \multicolumn{3}{|c|}{$20 \%$} & \multicolumn{3}{|c|}{$50 \%$} & \multicolumn{3}{|c|}{$80 \%$} \\
\hline & $2^{\circ} \mathrm{C}$ & $0^{\circ} \mathrm{C}$ & $-2^{\circ} \mathrm{C}$ & $2^{\circ} \mathrm{C}$ & $0^{\circ} \mathrm{C}$ & $-2^{\circ} \mathrm{C}$ & $2^{\circ} \mathrm{C}$ & $0^{\circ} \mathrm{C}$ & $-2^{\circ} \mathrm{C}$ \\
\hline Bethlehem & 15 -Oct & 29-Sep & 13-Sep & $01-$ Oct & 15-Sep & 31-Aug & 17-Sep & 2-Sep & 19-Aug \\
\hline Bloemfontein & $25-\mathrm{Oct}$ & 09-Oct & 24-Sep & $10-$ Oct & 21-Sep & 07-Sep & 26-Sep & 4-Sep & 20-Aug \\
\hline Bothaville & $02-\mathrm{Oct}$ & $02-\mathrm{Oct}$ & 31-Aug & 14-Sep & 14-Sep & 16-Aug & 29-Aug & 29-Aug & 28-Jul \\
\hline Fauresmith & 18-Oct & 25-Sep & 03-Sep & $01-O c t$ & 07-Sep & 20-Aug & 13-Sep & 22-Aug & 05-Aug \\
\hline Ficksburg & $22-\mathrm{Oct}$ & 29-Sep & 08-Sep & $03-\mathrm{Oct}$ & 12-Sep & 24-Aug & 14-Sep & 26-Aug & 10-Aug \\
\hline Frankfort & 16-Oct & 28-Sep & 12-Sep & 30-Sep & 15-Sep & 01-Sep & 16-Sep & 1-Sep & 21-Aug \\
\hline Virginia & $01-O c t$ & 12-Sep & 26-Aug & 16-Sep & 01-Sep & 14-Aug & 03-Sep & 21-Aug & 02-Aug \\
\hline Wepener & 24-Oct & $12-\mathrm{Oct}$ & 23-Sep & $11-$ Oct & 26-Sep & 09-Sep & 28-Sep & 10-Sep & 27-Aug \\
\hline Zastron & 26-Oct & $11-$ Oct & 21-Sep & 14-Oct & 26-Sep & 09-Sep & $02-$ Oct & 12-Sep & 29-Aug \\
\hline
\end{tabular}

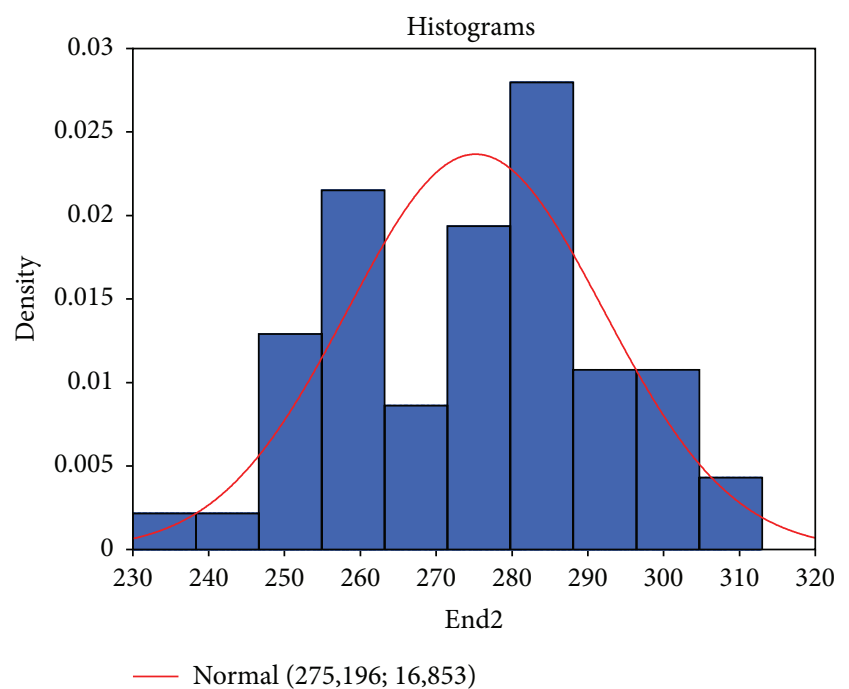

FIGURe 2: Probability fit with Normal distribution for cessation of light frost in Bethlehem.

the province with exceedance probability of $20 \%, 50 \%$, and $80 \%$ for light (medium) [heavy] frost on or after 1 October, 16 September, and 17 August (12 September, 1 September, and 17 August) [26 August, 14 August, and 28 July]. Occurrence of light (medium) [heavy] frost is mostly on or after 16 October, 30 September, and 13 September (25 September, 7 September, and 26 August) [8 September, 24 August, and 10 August] at $20 \%, 50 \%$, and $80 \%$ exceedance probability in the northeastern parts (vicinity of Frankfort, Bethlehem, and Ficksburg) and southwestern parts (vicinity of Fauresmith) of the province. Relatively late cessation of frost is evident over the central parts and high lying areas in the southeastern, eastern, and northeastern parts (vicinity of Wepener, Zastron, and Bloemfontein). Light (medium) [heavy] frost at $20 \%$, $50 \%$, and $80 \%$ is mostly experienced on or after 22 October, 10 October, and 26 September (9 October, 21 September, and 10 September) [21 September, 7 September, and 27 August]. As shown in Figure 3, the extremely late cessation of frost over Free State occurred between 26 October and 26 November (6 October and 26 November) [26 September and 26 November] for light, medium, and heavy frost, respectively. This is an indication that frost risk is high in Free State province with a chance of frost damage well within the rainfall season with the potential of damaging crops at the vegetative stage [5]. Time series of cessation of frost shows a lot of variation from one year to another with an average standard deviation of 19 days for all the frost thresholds (Figure 3).

3.3. Onset of Frost. Onset of frost at nonexceeding probabilities of $20 \%, 50 \%$, and $80 \%$ is latest over the northern parts of the province (neighbourhoods of Bothaville and Virginia) with light (medium) [heavy] frost occurring on or before 23 April, 4 May, and 17 May (11 May, 21 May, and 31 May) [21 May, 6 June, and 21 June] (Table 4). Over the northeastern parts (vicinity of Bethlehem, Frankfort, and Ficksburg) onset of frost at $20 \%, 50 \%$, and $80 \%$ nonexceeding probabilities for light (medium) [heavy] frost occurs on or before 15 April, 25 April, and 7 May (27 April, 7 May, and 19 May) [7 May, 17 May, and 28 May]. Frost over the southeastern, eastern, and northeastern parts (vicinity of Wepener, Zastron, and Bloemfontein) is earlier with the timing of light (medium) [heavy] frost at $20 \%, 50$, and $80 \%$ probability mostly being on or before 9 April, 18 April, and 28 April (20 April, 1 May, and 12 May) [1 May, 14 May, and 27 May]. Onset of frost for all three thresholds varies greatly over the years with the average standard deviation across all the stations for light, medium, and heavy frost of 13,14, and 16, days, respectively (Figure 4). Extremely early onset of frost ranges from 18 March to 29 March (29 March to 14 April) [1 April to 25 April] for light, medium, and heavy frost, respectively. This implies that frostsensitive crops have to be fully matured by mid-March in order to avoid frost damage (Figure 4).

3.4. Frost-Free Duration. The frost-free period spatial pattern follows that of the onset and cessation of frost. Areas of longest length of frost-free period are evident over the northern parts of the province with light (medium) [heavy] frost at $20 \%, 50 \%$, and $80 \%$ nonexceedance probability being 213, 231, and $254(245,263$, and 277) [278, 297, and 325] days or less (Table 5). Other areas over the northeastern parts like Bethlehem, Ficksburg, and Frankfort have their frost-free duration for light (medium) [heavy] frost at 20\%, $50 \%$, and $80 \%$ probability of less than or equal to 183,202 , and $225(218,238$, and 248) [240, 260, and 273] days. Areas 
TABLE 4: Onset of frost at different probability levels $(20 \%, 50 \%$, and $80 \%)$ and thresholds $\left(2^{\circ} \mathrm{C}, 0^{\circ} \mathrm{C}\right.$, and $\left.-2^{\circ} \mathrm{C}\right)$.

\begin{tabular}{|c|c|c|c|c|c|c|c|c|c|}
\hline \multirow{2}{*}{ Station } & \multicolumn{3}{|c|}{$20 \%$} & \multicolumn{3}{|c|}{$50 \%$} & \multicolumn{3}{|c|}{$80 \%$} \\
\hline & $2^{\circ} \mathrm{C}$ & $0^{\circ} \mathrm{C}$ & $-2^{\circ} \mathrm{C}$ & $2^{\circ} \mathrm{C}$ & $0^{\circ} \mathrm{C}$ & $-2^{\circ} \mathrm{C}$ & $2^{\circ} \mathrm{C}$ & $0^{\circ} \mathrm{C}$ & $-2^{\circ} \mathrm{C}$ \\
\hline Bethlehem & 15-Apr & 27-Apr & 07-May & 25-Apr & 06-May & 17-May & 03-May & 15-May & 28-May \\
\hline Bloemfontein & 12-Apr & 22-Apr & 03-May & 22-Apr & 01-May & 17-May & 02-May & 09-May & 30-May \\
\hline Bothaville & 20-Apr & 04-May & 18-May & 04-May & 17-May & 02-Jun & 17-May & 30-May & 18-Jun \\
\hline Fauresmith & 11-Apr & 26-Apr & 16-May & 25-Apr & 10-May & 01-Jun & 10-May & 23-May & 19-Jun \\
\hline Ficksburg & 13-Apr & 26-Apr & 17-May & 25-Apr & 07-May & 29-May & 07-May & 19-May & 10-Jun \\
\hline Frankfort & 11-Apr & 22-Apr & 01-May & 22-Apr & 01-May & 12-May & 30-Apr & 09-May & 23-May \\
\hline Virginia & 23-Apr & 11-May & 21-May & 03-May & 21-May & 06-Jun & 14-May & 31-May & 21-Jun \\
\hline Wepener & 09-Apr & 20-Apr & 01-May & 18-Apr & 01-May & 14-May & 28-Apr & 12-May & 27-May \\
\hline Zastron & 08-Apr & 19-Apr & 01-May & 18-Apr & 30-Apr & 14-May & 28-Apr & 11-May & 27-May \\
\hline
\end{tabular}

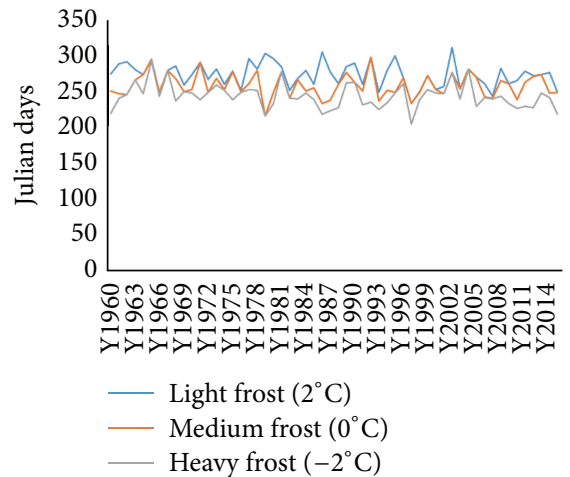

(a)

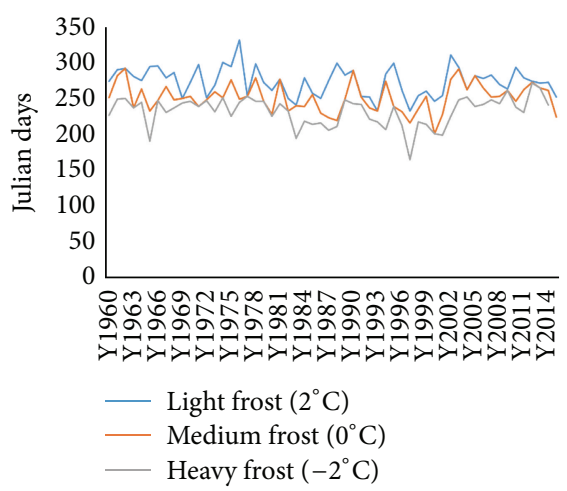

(d)

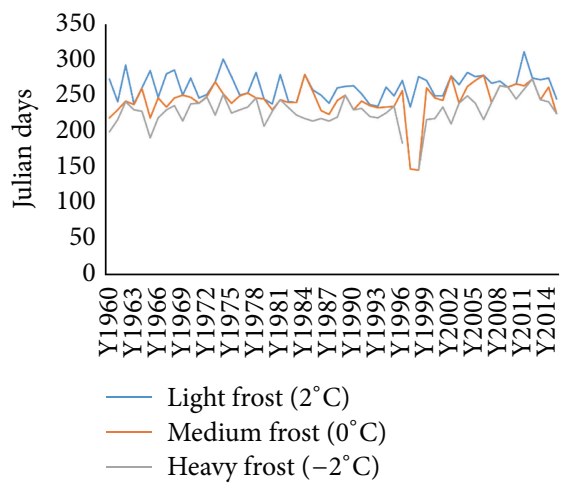

(g)

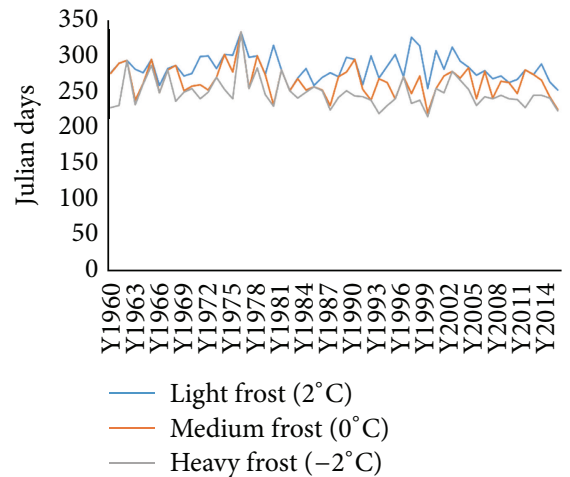

(b)

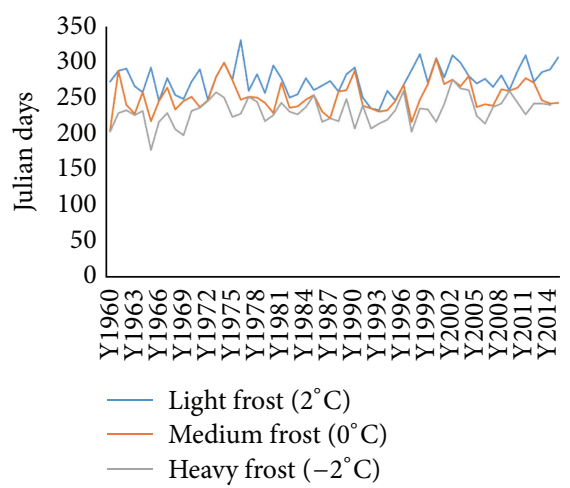

(e)

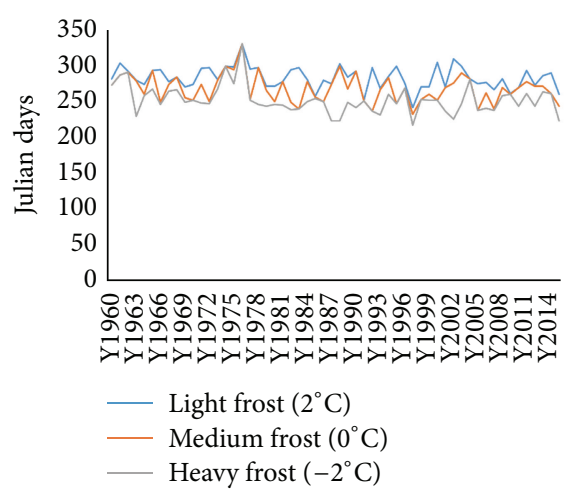

(h)

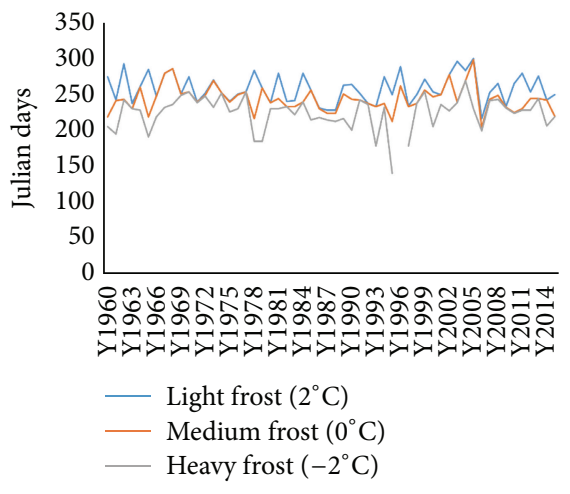

(c)

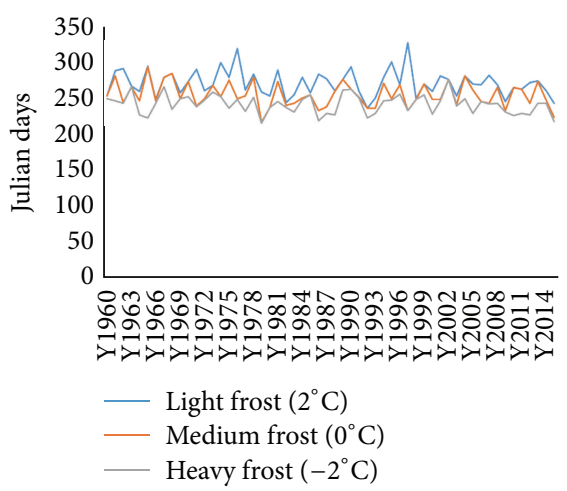

(f)

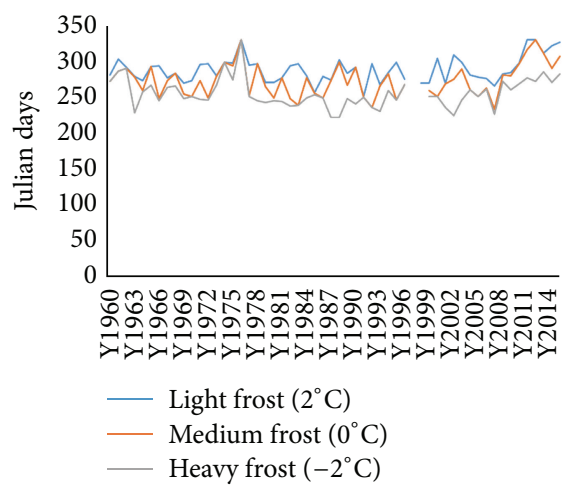

(i)

Figure 3: Time series of cessation of frost in Julian days from 1960 to 2015 for (a) Bethlehem, (b) Bloemfontein, (c) Bothaville, (d) Fauresmith, (e) Ficksburg, (f) Frankfort, (g) Virginia, (h) Wepener, and (i) Zastron. 
TABle 5: Frost-free duration (in days) at different probability levels $(20 \%, 50 \%$, and $80 \%)$ and thresholds $\left(2^{\circ} \mathrm{C}, 0^{\circ} \mathrm{C}\right.$, and $\left.-2^{\circ} \mathrm{C}\right)$.

\begin{tabular}{|c|c|c|c|c|c|c|c|c|c|}
\hline \multirow{2}{*}{ Station } & \multicolumn{3}{|c|}{$20 \%$} & \multicolumn{3}{|c|}{$50 \%$} & \multicolumn{3}{|c|}{$80 \%$} \\
\hline & $2^{\circ} \mathrm{C}$ & $0^{\circ} \mathrm{C}$ & $-2^{\circ} \mathrm{C}$ & $2^{\circ} \mathrm{C}$ & $0^{\circ} \mathrm{C}$ & $-2^{\circ} \mathrm{C}$ & $2^{\circ} \mathrm{C}$ & $0^{\circ} \mathrm{C}$ & $-2^{\circ} \mathrm{C}$ \\
\hline Bethlehem & 179 & 218 & 240 & 200 & 235 & 260 & 220 & 248 & 276 \\
\hline Bloemfontein & 175 & 201 & 244 & 194 & 222 & 259 & 212 & 243 & 273 \\
\hline Bothaville & 209 & 243 & 269 & 231 & 256 & 297 & 254 & 270 & 325 \\
\hline Fauresmith & 185 & 221 & 262 & 207 & 246 & 287 & 232 & 271 & 314 \\
\hline Ficksburg & 183 & 216 & 261 & 202 & 238 & 278 & 225 & 260 & 295 \\
\hline Frankfort & 183 & 215 & 238 & 202 & 232 & 253 & 221 & 245 & 268 \\
\hline Virginia & 213 & 245 & 278 & 231 & 263 & 293 & 246 & 277 & 308 \\
\hline Wepener & 173 & 198 & 226 & 189 & 221 & 245 & 207 & 239 & 265 \\
\hline Zastron & 173 & 195 & 229 & 187 & 218 & 247 & 201 & 237 & 265 \\
\hline
\end{tabular}

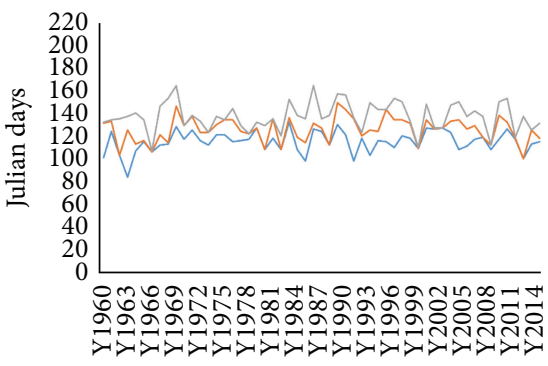

— Light frost $\left(2^{\circ} \mathrm{C}\right)$

- Medium frost $\left(0^{\circ} \mathrm{C}\right)$

— Heavy frost $\left(-2^{\circ} \mathrm{C}\right)$

(a)

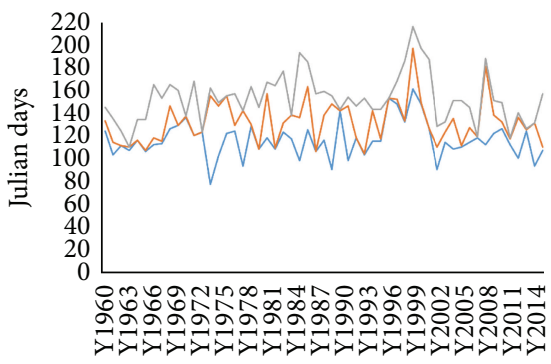

- Light frost $\left(2^{\circ} \mathrm{C}\right)$

- Medium frost $\left(0^{\circ} \mathrm{C}\right)$

— Heavy frost $\left(-2^{\circ} \mathrm{C}\right)$

(d)

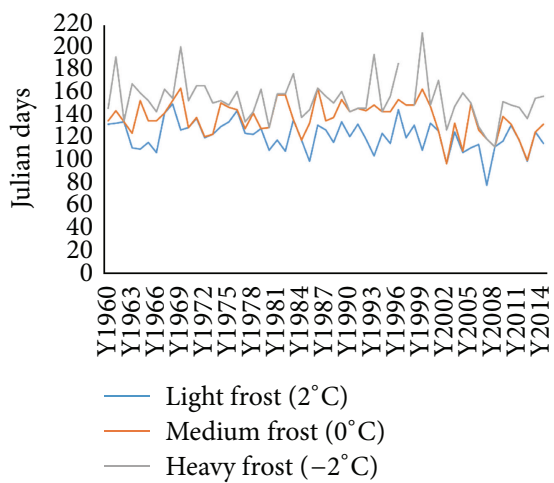

(g)

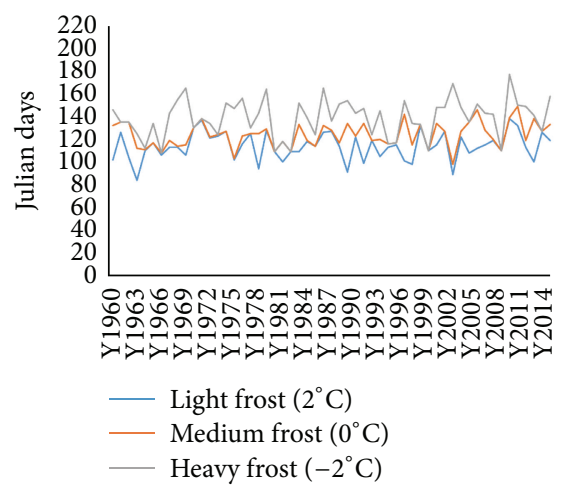

(b)

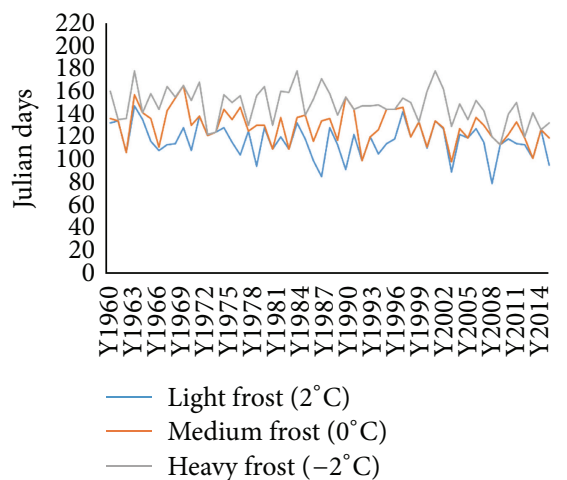

(e)

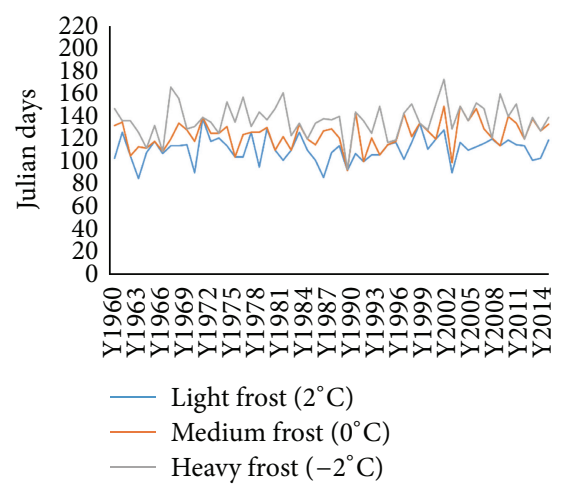

(h)

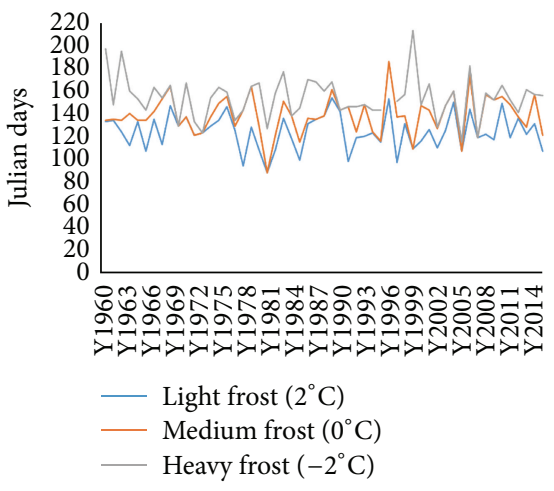

(c)

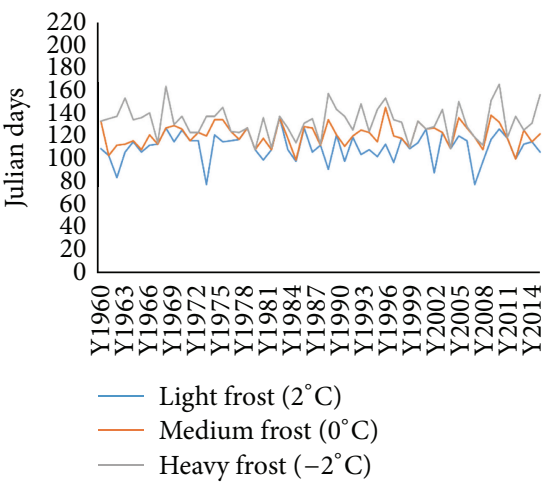

(f)

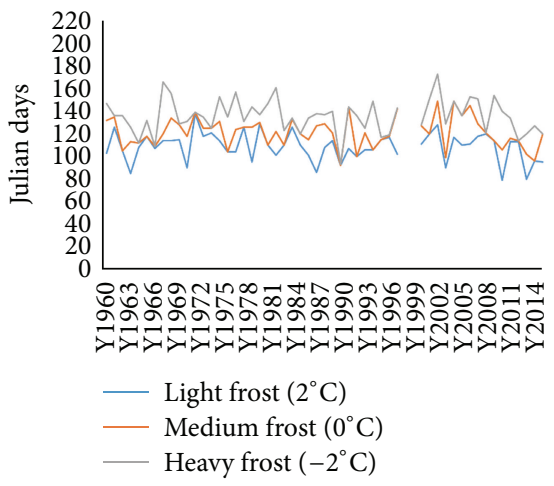

(i)

Figure 4: Time series of onset of frost in Julian days from 1960 to 2014 for (a) Bethlehem, (b) Bloemfontein, (c) Bothaville, (d) Fauresmith, (e) Ficksburg, (f) Frankfort, (g) Virginia, (h) Wepener, and (i) Zastron. 


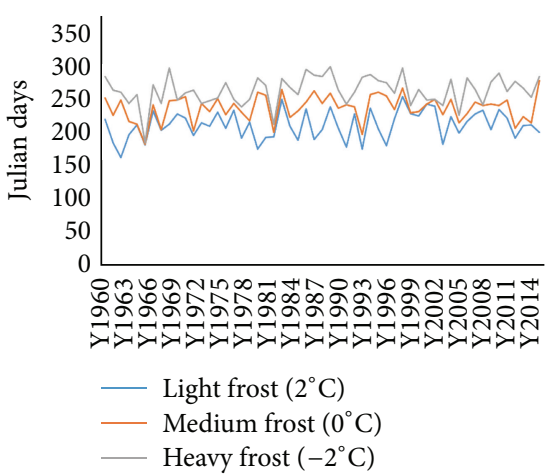

(a)

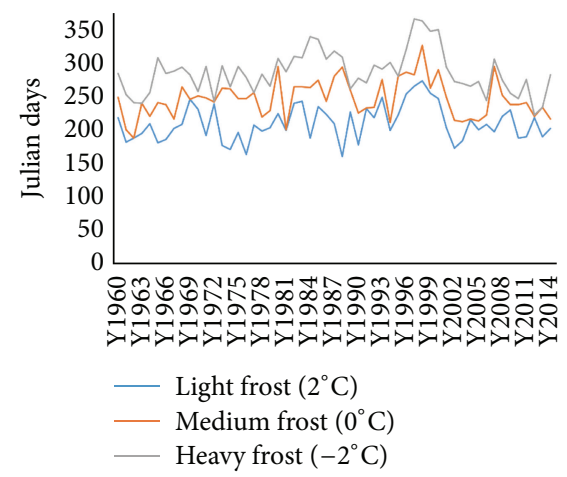

(d)

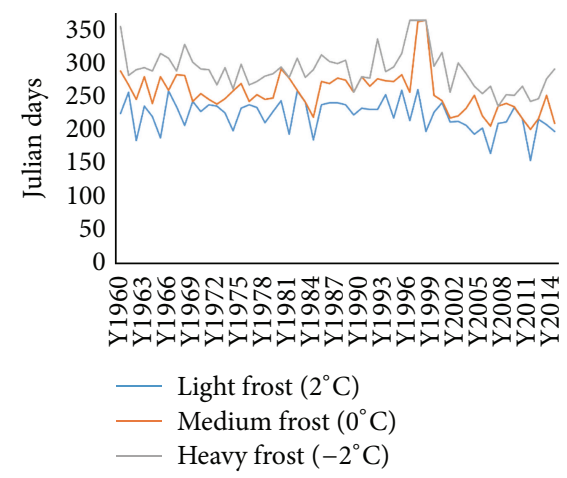

(g)

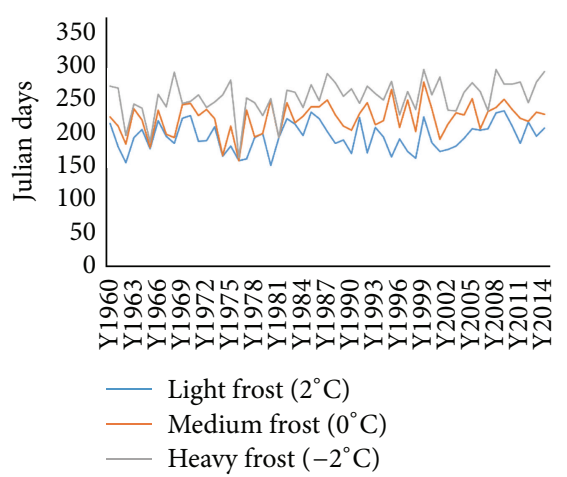

(b)

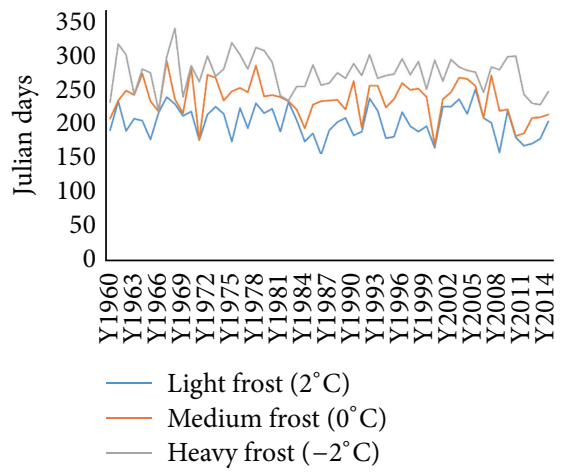

(e)

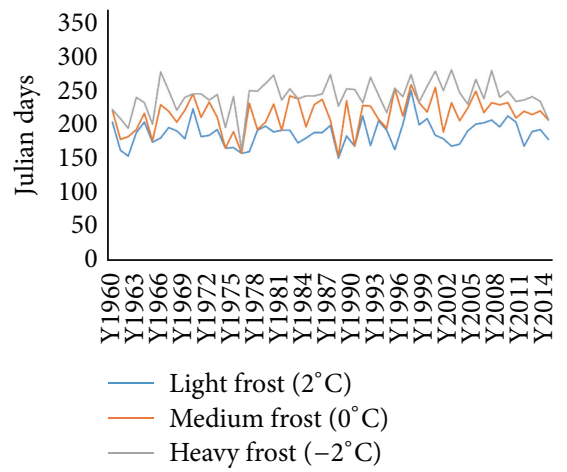

(h)

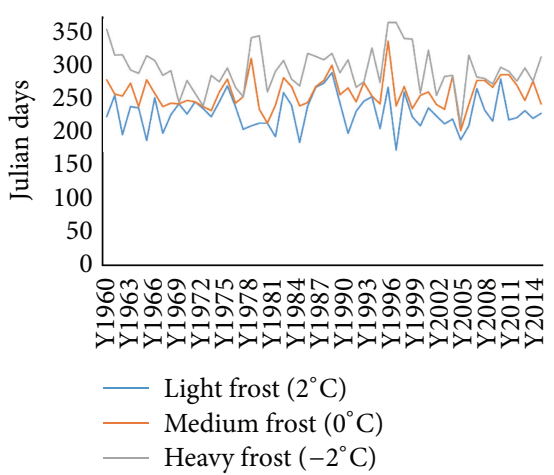

(c)

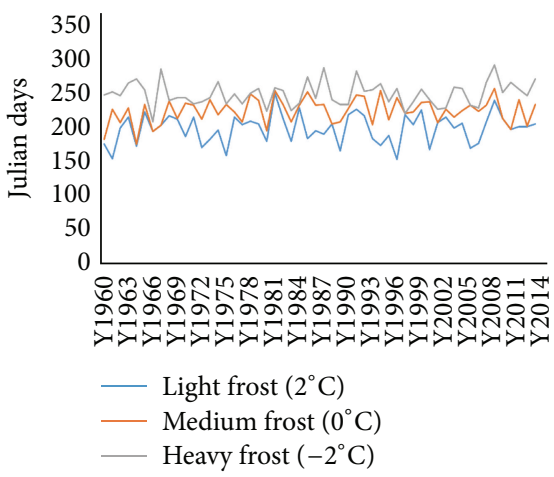

(f)

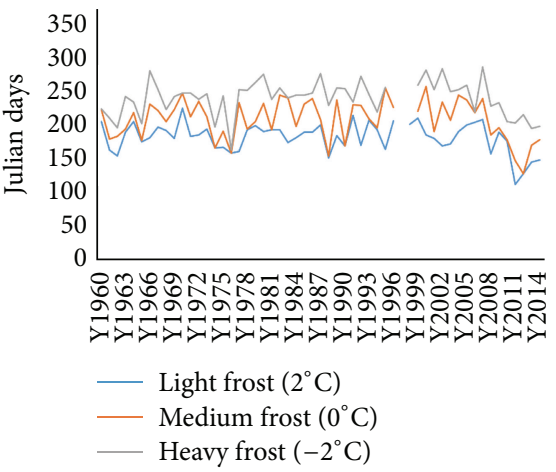

(i)

Figure 5: Time series of frost-free duration in days from 1960 to 2014 for (a) Bethlehem, (b) Bloemfontein, (c) Bothaville, (d) Fauresmith, (e) Ficksburg, (f) Frankfort, (g) Virginia, (h) Wepener, and (i) Zastron.

of short frost-free season are mostly over the southeastern parts, close to the escarpments along the border with Lesotho. Frost-free duration for light (medium) [heavy] at 20\%, 50\%, and $80 \%$ in these areas is mostly equal to or less than 173 , 189, and 207 (198, 221, and 239) [226, 245, and 265] days. Year to year variation of frost-free period is high over Free State province, as depicted in Figure 5, with average standard deviation of 23, 25, and 26 days for light, medium, and heavy frost, respectively.

3.5. Trends in Frost Indices. Cessation of frost over Free State province mostly shows a negative trend which is significant at $10 \%$ significance level for the $2^{\circ} \mathrm{C}$ and $0^{\circ} \mathrm{C}$ thresholds, while at $-2^{\circ} \mathrm{C}$ the threshold trend is significant at $5 \%$ significance level (Table 6). Negative trends show that cessation of frost is becoming earlier over time implying that planting of crops can be early depending on the soil water content status. In most places, cessation of frost becomes earlier by an average of 2,3, and 4 days per decade for light, medium, and heavy frost. In contrast, significant positive trends are obtained in Virginia and Ficksburg whereby cessation of frost is becoming later by an average of 3 days per decade for all the frost thresholds. Onset of frost mostly shows nonsignificant positive trends in most parts of Free State with the exception of Virginia and Ficksburg showing a significant negative trend. Subsequently, frost-free duration is mostly positive for the province with significant trends at Bethlehem (light frost) [ 2 to 3 days' increase per decade], Bloemfontein (medium and 
TABLE 6: Trends in frost indices for Free State province of South Africa.

\begin{tabular}{lccccccccc}
\hline \multirow{2}{*}{ Station } & \multicolumn{3}{c}{ Cessation of frost } & \multicolumn{3}{c}{ Onset of frost } & \multicolumn{3}{c}{ Frost-free duration } \\
& $2^{\circ} \mathrm{C}$ & $0^{\circ} \mathrm{C}$ & $-2^{\circ} \mathrm{C}$ & $2^{\circ} \mathrm{C}$ & $00^{\circ} \mathrm{C}$ & $-2^{\circ} \mathrm{C}$ & $2^{\circ} \mathrm{C}$ & $0^{\circ} \mathrm{C}$ & $-2^{\circ} \mathrm{C}$ \\
\hline Bethlehem & $\mathrm{Neg}^{(\mathrm{NS})}$ & $\mathrm{Neg}^{(\mathrm{NS})}$ & $\mathrm{Neg}^{(*)}$ & $\mathrm{Pos}^{(\mathrm{NS})}$ & $\mathrm{Pos}^{(\mathrm{NS})}$ & $\mathrm{Pos}^{(\mathrm{NS})}$ & $\mathrm{Pos}^{(* *)}$ & $\mathrm{Pos}^{(\mathrm{NS})}$ & $\mathrm{Pos}^{(\mathrm{NS})}$ \\
Bloemfontein & $\mathrm{Neg}^{(* *)}$ & $\mathrm{Neg}^{(*)}$ & $\mathrm{Neg}^{(*)}$ & $\mathrm{Pos}^{(\mathrm{NS})}$ & $\mathrm{Pos}^{(\mathrm{NS})}$ & $\mathrm{Pos}^{(* *)}$ & $\mathrm{Pos}^{(\mathrm{NS})}$ & $\mathrm{Pos}^{(*)}$ & $\mathrm{Pos}^{(*)}$ \\
Bothaville & $\mathrm{Neg}^{(\mathrm{NS})}$ & $\mathrm{Neg}^{(\mathrm{NS})}$ & $\mathrm{Neg}^{(\mathrm{NS})}$ & $\mathrm{Neg}^{(\mathrm{NS})}$ & $\mathrm{Pos}^{(\mathrm{NS})}$ & $\mathrm{Neg}^{(\mathrm{NS})}$ & $\mathrm{Neg}^{(\mathrm{NS})}$ & $\mathrm{Pos}^{(\mathrm{NS})}$ & $\mathrm{Neg}^{(\mathrm{NS})}$ \\
Fauresmith & $\mathrm{Neg}^{(* *)}$ & $\mathrm{Neg}^{(\mathrm{NS})}$ & $\mathrm{Neg}^{(\mathrm{NS})}$ & $\mathrm{Pos}^{(\mathrm{NS})}$ & $\mathrm{Pos}^{(\mathrm{NS})}$ & $\mathrm{Pos}^{(\mathrm{NS})}$ & $\mathrm{Pos}^{(\mathrm{NS})}$ & $\mathrm{Pos}^{(\mathrm{NS})}$ & $\mathrm{Pos}^{(\mathrm{NS})}$ \\
Ficksburg & $\mathrm{Pos}^{(* *)}$ & $\mathrm{Pos}^{(* *)}$ & $\mathrm{Pos}^{(*)}$ & $\mathrm{Neg}^{(*)}$ & $\mathrm{Neg}^{(*)}$ & $\mathrm{Neg}^{(\mathrm{NS})}$ & $\mathrm{Neg}^{(*)}$ & $\mathrm{Neg}^{(*)}$ & $\mathrm{Neg}^{(*)}$ \\
Frankfort & $\mathrm{Neg}^{(\mathrm{NS})}$ & $\mathrm{Neg}^{(* *)}$ & $\mathrm{Neg}^{(*)}$ & $\mathrm{Pos}^{(\mathrm{NS})}$ & $\mathrm{Pos}^{(\mathrm{NS})}$ & $\mathrm{Neg}^{(\mathrm{NS})}$ & $\mathrm{Pos}^{(\mathrm{NS})}$ & $\mathrm{Pos}^{(\mathrm{NS})}$ & $\mathrm{Neg}^{(\mathrm{NS})}$ \\
Virginia & $\mathrm{Pos}^{(\mathrm{NS})}$ & $\mathrm{Pos}^{(*)}$ & $\mathrm{Pos}^{(*)}$ & $\mathrm{Neg}^{(*)}$ & $\mathrm{Neg}^{(*)}$ & $\mathrm{Neg}^{(* *)}$ & $\mathrm{Neg}^{(*)}$ & $\mathrm{Neg}^{(*)}$ & $\mathrm{Neg}^{(*)}$ \\
Wepener & $\mathrm{Neg}^{(*)}$ & $\mathrm{Neg}^{(*)}$ & $\mathrm{Neg}^{(*)}$ & $\mathrm{Pos}^{(\mathrm{NS})}$ & $\mathrm{Pos}^{(* *)}$ & $\mathrm{Pos}^{(\mathrm{NS})}$ & $\mathrm{Pos}^{(\mathrm{NS})}$ & $\mathrm{Pos}^{(*)}$ & $\mathrm{Pos}^{(* *)}$ \\
Zastron & $\mathrm{Pos}^{(\mathrm{NS})}$ & $\mathrm{Neg}^{(\mathrm{NS})}$ & $\mathrm{Neg}^{(\mathrm{NS})}$ & $\mathrm{Neg}^{(\mathrm{NS})}$ & $\mathrm{Neg}^{(\mathrm{NS})}$ & $\mathrm{Neg}^{(\mathrm{NS})}$ & $\mathrm{Neg}^{(\mathrm{NS})}$ & $\mathrm{Neg}^{(\mathrm{NS})}$ & $\mathrm{Pos}^{(\mathrm{NS})}$ \\
\hline
\end{tabular}

Pos = positive; Neg = negative; ${ }^{(*)}$ significant at $5 \% ;{ }^{(*)}$ significant at $10 \% ;{ }^{(\mathrm{NS})}$ not significant.

heavy frost) [ 2 to 5 days' increase per decade], and Wepener (medium and heavy frost) [2 to 5 days' increase per decade]. Positive trends are an indication that minimum temperatures are increasing with time over the region, implying an increase of favourable conditions for crops that are sensitive to low temperatures. In contrast, significant negative trends are evident in Ficksburg and Virginia at a rate ranging from 2 to 6 days per decade.

\section{Discussion}

Frost analysis is important because knowledge of the frequency and timing of frosts will help reduce the risk of frost damage in vulnerable areas [19]. The present study investigated frost risk assessment in Free State province of South Africa at different thresholds $\left(-2^{\circ} \mathrm{C}, 0^{\circ} \mathrm{C}\right.$, and $\left.2^{\circ} \mathrm{C}\right)$ taking into consideration multiple risk levels (20\%, 50\%, and $80 \%$ exceedance). Probable dates for the first frost and last frost of the growing season can also help farmers in preventing or reducing the damage to agricultural produce caused by frost [11]. Consequently, knowledge of the frost-free period can be used as a proxy for the length of time available for crop production [20].

The assessment of frost occurrence in Free State showed considerable variation from one place to another owing to the vast differences in topography over the province. The results of the frost risk assessment show earlier frost onset, late cessation of frost, and shorter growing period over the northeastern, central, eastern, and southeastern parts. These areas are more vulnerable to frost especially if planting is early and this forces farmers to delay their planting resulting in shorter growing periods suitable for short or medium cultivars [5]. Late planted crops in these areas are also in danger of not achieving full maturity before suffering from damage resulting in poor quality yield or production loss in extreme cases. The first frost at the onset of a frost period causes damage to crops at their later stages of development, while the last frost at the cessation of the frost period damages seedlings and young plants [11, 21]. Farmers in these regions are advised to plant short season varieties taking into consideration all the frost indices. Trends in frost indices are mostly favourable for increasing frost-free period implying that the planting of relatively longer cultivars might be suitable in the future depending on the rate of frost-free period increase. The length of the frost-free period denotes the growing period, and, in Free State, it is mostly between 160 days and over 330 days, depending on the temperature threshold and locality. Long frost-free periods are evident over patches in the far western and northeastern Free State. These areas have low frost risk but it does not mean they are the most desirable places for planting maize or any other crops sensitive to frost damage under rain-fed conditions as there are other climate risks like rainy season length and agricultural drought that have to be considered [22].

In Free State, the frost differences in the risk levels between onset and cessation of frost were mostly 10 days from one risk level to another at all the temperature thresholds which does not denote vast temporal differences to the advantage of crop management in the province. Depending on the timing of the onset of rains, which normally runs parallel with cessation of frost in southern Africa, farmers are advised to utilize either the $50 \%$ or the most risk averse level (20th exceedance probability) to minimize crop losses at the seedling stage. Targeting of maturity before the onset of frost should be the practice without compromising on crop yield. In some places, like the eastern Free State, careful consideration of the cultivar which has a high potential but requires relatively lower heat units accumulation is desirable.

\section{Conclusion}

The spatial patterns of the frost indices at $20 \%, 50 \%$, and $80 \%$ probability are similar. Overall, very late cessation of frost occurs over the east and southeastern Free State. These areas are also characterized by very early onsets resulting in shorter frost-free periods as compared to other regions. In these areas, planting early would definitely harm the seedlings while planting very late would result in crops not attaining their full maturity before the risk of frost increases. The window for planting is therefore relatively short in these places. In contrast, most parts of the northern, western, and southwestern Free State experience relatively long growing periods making them ideal for planting long-season crops providing that other climate requirements have low risk in 
those areas. In general, the results show low frost risk in the far western parts of the province, increasing gradually towards the east where the late frost cessation and early onset risks are high. Trend analysis showed a tendency of positive trends of frost-free period in some areas implying an increase in minimum temperatures with time. The rate of increase in frost-free period ranges from 1 to 5 days per decade depending on the location and severity of frost.

\section{Competing Interests}

The authors declare that there is no conflict of interests regarding the publication of this paper.

\section{Acknowledgments}

The authors are grateful for funding by the Department of Agriculture, Forestry and Fisheries (Project no. 000544). The authors thank Dr. Thomas Fyfield of the Agricultural Research Council for editing the manuscript.

\section{References}

[1] M. Smale and T. Jayne, Maize in Eastern and Southern Africa: 'Seeds' of Success in Retrospect, EPTD Discussion Paper no. 97, IFPRI, Washington, DC, USA, 2003, http://www.fao.org/docs/ eims/upload/166420/Smale,Jayne.pdf.

[2] FAOSTAT, "Food and Agricultural Commodities Production," http://faostat.fao.org/site/339/default.aspx.

[3] Department of Agriculture, Forestry, and Fisheries, "Abstract of agricultural statistics," Directorate Statistics and Economic Analysis, Pretoria, South Africa, 2013, http://www.daff.gov.za/ docs/statsinfo/Abstact2013.pdf.

[4] J. M. de Jager, A. B. Potgieter, and W. J. van den Berg, "Framework for forecasting the extent and severity of drought in maize in the Free State Province of South Africa," Agricultural Systems, vol. 57, no. 3, pp. 351-365, 1998.

[5] M. E. Moeletsi, Agroclimatological risk assessment of rain-fed maize production for the Free State Province of South Africa [Ph.D. thesis], Department of Soil, Crop and Climate Sciences, University of the Free State, Bloemfontein, South Africa, 2010.

[6] J. Allemann, "Crop studies for the Frankfort, Reitz and Vrede Magisterial Districts," Tech. Rep. GW/A/97/71, Agricultural Research Council, Vegetable and Ornamental Plant Institute, Pretoria, South Africa, 1997.

[7] J. van den Berg, C. Manley, and H. Strauss, Climatic Suitability and Production Risk for Selected Agricultural Commodities in the Free State, Report prepared by EnViro Vision, Free State Department of Agriculture, Bloemfontein, South Africa, 2002.

[8] M. E. Moeletsi, K. M. Nape, P. Magama et al., "Mitigation and adaptation to climate variability and change in the Thabo Mofutsanyane district (Free State Province, South Africa): A multi-disciplinary approach through integrated crop-livestock system," Report for the Department of Agriculture, Forestry and Fisheries, Pretoria, South Africa, pp. 83, 2015.

[9] V. Varshavian, N. Ghahreman, A. Khalili, and S. Hajjam, "Statistical analysis of first and last frost occurrences and length of frost free period during the past decades in different regions of Iran," in Proceedings of the 6th International Conference on Environmental Informatics, ISEIS 2007, tha, November 2007.
[10] A. Tait and X. Zheng, "Mapping frost occurrence using satellite data," Journal of Applied Meteorology, vol. 42, no. 2, pp. 193-203, 2003.

[11] M. Rahimi, S. Hajjam, A. Khalili, G. A. Kamali, and C. J. Stigter, "Risk analysis of first and last frost occurrences in the Central Alborz region, Iran," International Journal of Climatology, vol. 27, no. 3, pp. 349-356, 2007.

[12] M. E. Moeletsi, S. Walker, and W. A. Landman, "Frost risk assessment in the Free State," in Proceedings of the 25th Annual South African Society for Atmospheric Sciences Conference (SASAS '09), 2 pages, Cape Town, South Africa, September 2009.

[13] F. Zenoni, G. Antolini, T. Campisi, V. Marletto, and F. Rossi, "Characteristics of Emilia-Romagna region in relation with late frost risk," Physics and Chemistry of the Earth, vol. 27, no. 23-24, pp. 1091-1101, 2002.

[14] Z. Hejazizadeh and M. H. Naserzadeh, "Calculation and analysis of frost duration times by using Delphi programming: a case study in Lorestan, Iran," Journal of Applied Sciences, vol. 7, no. 23, pp. 3831-3835, 2007.

[15] G. Trasmonte, R. Chavez, B. Segura, and J. L. Rosales, "Frost risks in the Mantaro river basin," Advances in Geosciences, vol. 14, pp. 265-270, 2008.

[16] Alberta Atlas, "Agroclimatic Atlas of Alberta: Agricultural Climate Elements," 2015, http://wwwl.agric.gov.ab.ca/\$department/deptdocs.nsf/all/sag6301.

[17] A. Bootsma and D. M. Brown, "Freeze protection methods for crops," Fact Sheet ISNN 1198-712X, Ministry of Agriculture, Food and Rural Affairs, Ontario, Canada, 1985.

[18] Y. Xia, P. Fabian, A. Stohl, and M. Winterhalter, "Forest climatology: estimation of missing values for Bavaria, Germany," Agricultural and Forest Meteorology, vol. 96, no. 1-3, pp. 131-144, 1999.

[19] A. Tait and X. Zheng, "Mapping frost occurrence using satellite data," Journal of Applied Meteorology, vol. 42, no. 2, pp. 193-203, 2003.

[20] V. Varshavian, N. Ghahreman, A. Khalili, and S. Hajjam, "Statistical analysis of first and last frost occurrences and length of frost free period during the past decades in different regions of Iran," Environmental Informatics Archives, vol. 5, pp. 631-637, 2007.

[21] A. J. Vega, K. D. Robbins, and J. M. Grymes, "Frost/freeze analysis in the southern climate region," Southern Regional Climate Center, pp. 96, 1994, http://www.srh.noaa.gov/images/ oun/climate/srcc/srcc1994.pdf.

[22] M. E. Moeletsi and S. Walker, "A simple agroclimatic index to delineate suitable growing areas for rainfed maize production in the Free State Province of South Africa," Agricultural and Forest Meteorology, vol. 162-163, pp. 63-70, 2012. 

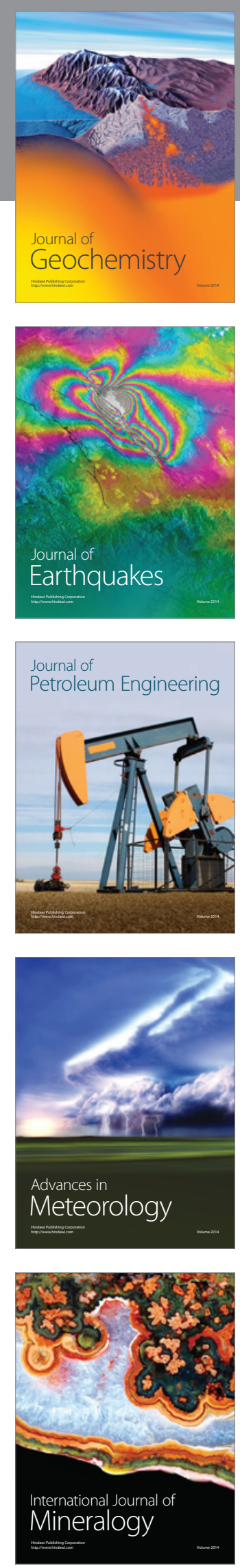
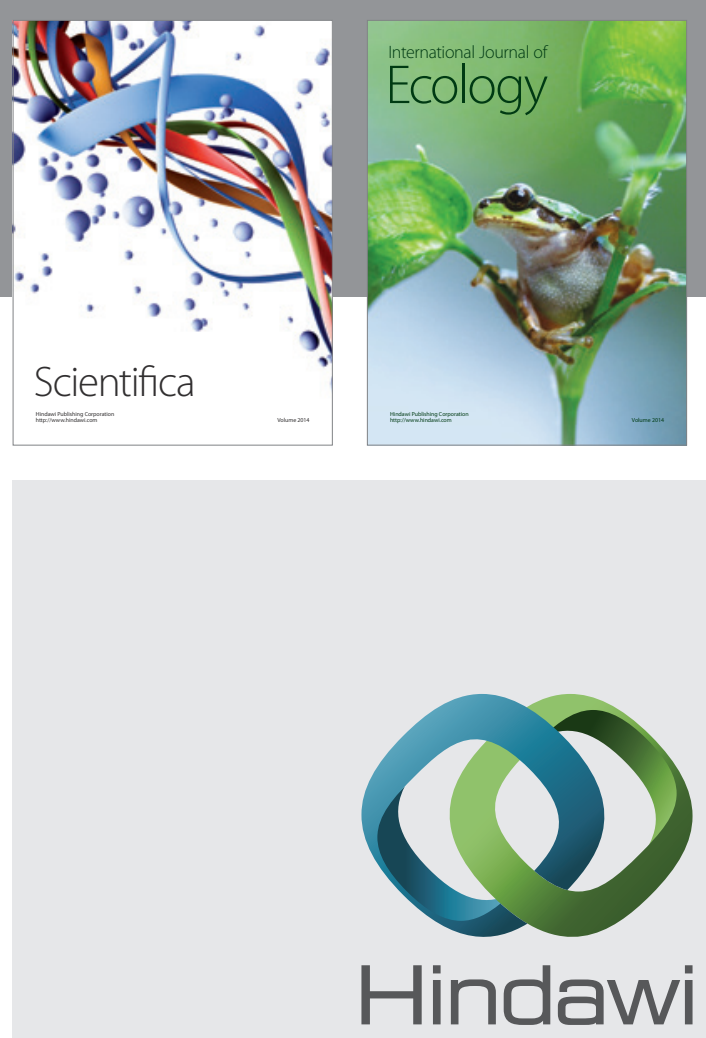

Submit your manuscripts at

http://www.hindawi.com
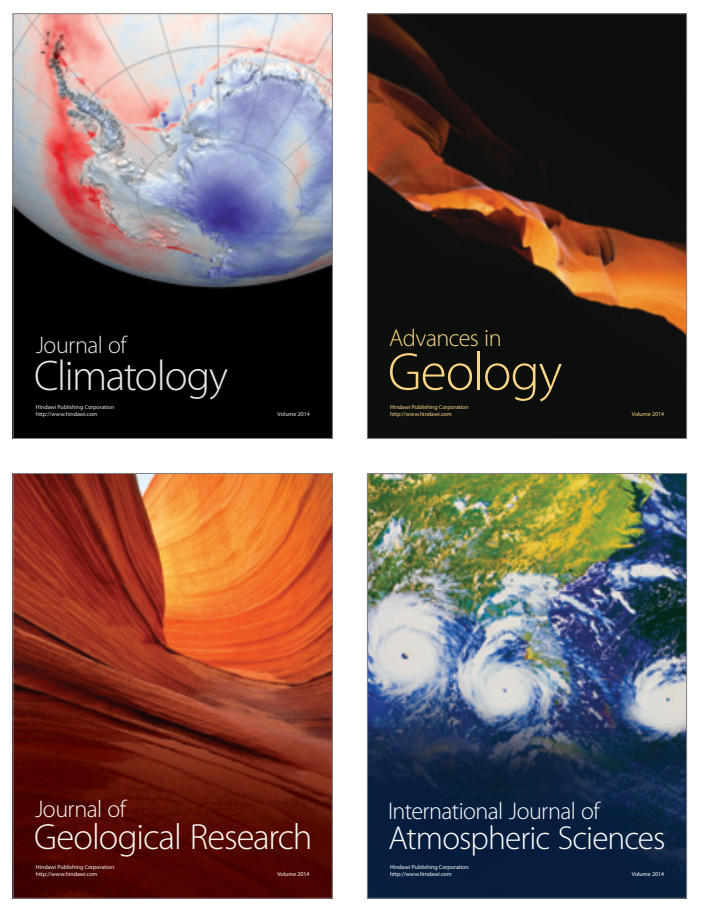

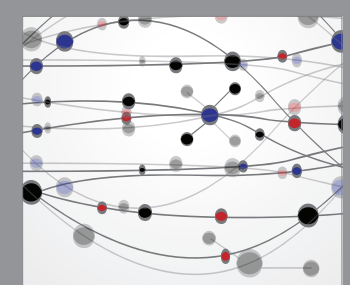

The Scientific

\section{World Journal}
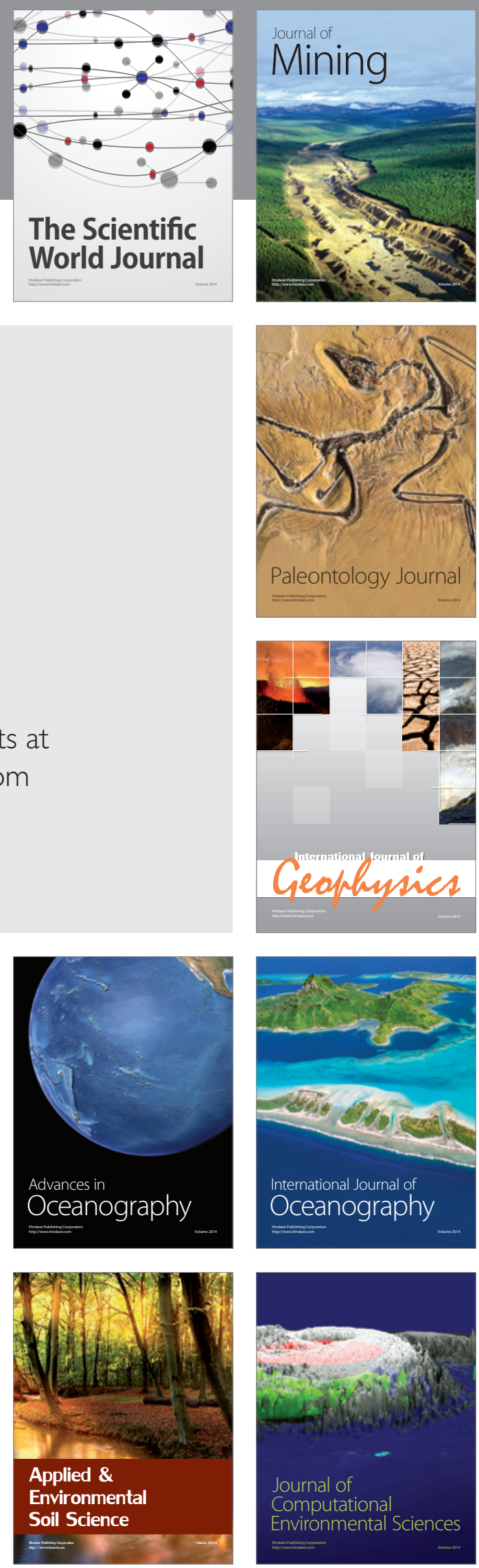